\title{
Analysis of the Czech Advertising Market and its Main Players
}

\author{
Michal Konečný ${ }^{1, *}$, Róbert Világi ${ }^{2}$, Yaroslava Kostiuk $^{1,3}$, František Pollák ${ }^{1}$ \\ ${ }^{1}$ Institute of Technology and Business, Faculty of Corporate Strategy, Okruzni 517/10, 37001 Ceske Budejovice, Czech Republic \\ ${ }^{2}$ University of Economics in Bratislava, Faculty of Business Management, Dolnozemska cesta 1, 85235 Bratislava, Slovakia \\ ${ }^{3}$ University of Zilina, Faculty of Operation and Economics of Transport and Communications, Univerzitna 1, 01026 Zilina, Slovakia
}

\begin{abstract}
At a time of global crisis, also at a time of accelerated digitalisation of businesses, sensible investment in communication with their customers is becoming very topical. The paper focuses on the development of investments in Internet advertising in the period 2012-2020. The method used for the research was a comparative analysis, which showed that the amount of money invested in internet advertising increased every year and that, unlike other types of advertising, no year was recorded for internet advertising during the period under review, when the value of investments in a given year would be lower than the value in the previous year. The results show that online advertising is taking an increasing share of total advertising investment. Another finding is that television advertising maintains a dominant position in the advertising market and is not directly affected by the development of investment in Internet advertising. However, the growth of investment in Internet advertising has a direct impact on the volume of investment in print advertising and $\mathrm{OOH}$ (Out of Home) advertising. The given types of media showed the largest decrease in terms of market share and negatively copied the development of investments in Internet advertising. In the case of radio advertising, there was also a decrease, but its dependence on Internet advertising has not been proven. However, the question arises as to the development of investments in the coming years. It is possible to anticipate the continuing strengthening of the role of Internet advertising and it will also be interesting to see whether Internet advertising will jeopardize the position of TV advertising. The results of the research will help both researchers and companies in the process of their decision to invest in selected types of advertising.
\end{abstract}

Keywords: advertising market; investments; internet advertising; strategic management

\section{Introduction}

Today, the digital world is an integral part of corporate culture, and not only corporate data, but also data about customers and customer behavior is an integral part of the company. A significant competitive advantage for the SME sector is the availability of cutting-edge technologies and technological progress, but not every company uses the offered technologies of the digital world. Today's manager must follow current trends and customer behavior, because today he already has access to technology without significant investments. According to figures from the Czech Statistical Office [1], $82 \%$ of Czech households already had access to the Internet in 2020, and 54\% of the human population shop online. It can be seen that Czech entrepreneurs have also become aware of this trend, and in recent years they have placed more emphasis on activities in this communication channel. The Internet has thus become an irreplaceable tool for the acquisition of new customers of domestic companies. The aim of this paper is to find out how advertisers were willing to invest in Internet advertising in the period 2012-2020 and how the phenomenon affected the amount of investment in other forms of advertising. Television advertising, print, radio and $\mathrm{OOH}$ - Out of Home advertising, which represents the types of advertising affecting the advertising audience away from home, will be considered as other forms of advertising.

\subsection{Current State of the Adressed Problem at Home and Abroad}

Misuraca, Scepi and Spano [2] state that the advent of Web 2.0 has changed everyday life in many ways, such as a system involving the purchase of products and the use of services, so that the revolution has inevitably affected businesses by making customers increasingly demanding. Vila, Cardoso and de Araujo [3] argue that communication is a key tool for informing consumers about products and services. They argue that the current consumer trends that come with new technologies and the Internet must be considered when creating a communication strategy with consumers, thus creating the concept of 2.0 communication. Opresnik [4] states that in the context of the growing popularity of social networks, blogs and podcasts, customers can spread their views on products or services to potentially millions of audiences, and

\footnotetext{
* Corresponding author: 27826@mail.vstecb.cz
} 
that with the expansion of people's Internet access, anyone interested in addressing product problems and services provided by companies to deal with them.

Pollak et al. [5] state that the COVID-19 pandemic redefined the practices in all business sectors, as in the first half of 2020, companies faced an upredictable and unexpected situation which turned into both threats and opportunities. As a result, brick-and-mortar branches of most stores were closed and a significnt part of business transactions and activities has moved to the online environment. Khurramov and Fayzieva [6] the term new media refers to traditional and different ways of providing information to consumers based on the latest digital technologies. Khajehasani, Abolizadeh and Dehyadegari [7] say that, as technological progress grows, so does the number of Internet users, and Internet communication has become the routine of the 21 st century. The Internet as a means of providing business products and services is already a common tool and even necessary for some businesses. Soviar et al. [8] state that the digital environment is playing an increasingly important role in the customer's decision-making. Pollák and Markovič [9] claim that it is also a place for sharing the customer's opinions and experiences with a specific company, where a dissatisfied customer can pose a reputational risk to the company.

Kumar and Mittal [10] state that, because interactions take place anywhere and anytime, they go far beyond the traditional customer connection. Brown and Hayes [11] state that the consumer is exposed to more than a thousand advertisements before going to bed. Zhang et al. [12] state that in the case of financial market trading, online advertising is based on real-time bidding and uses an auction mechanism to automate media purchases. Therefore, how optimally the bids are submitted is crucial for increasing profit and return on investment. The high risk of user behavior and the uncertainty of costs caused by auction competition can lead to significant risk in estimating campaign performance. Gasilov et al. [13] state that the effectiveness of advertising is determined not only by the number of people who come into visual contact with the advertising media, but also by the degree to which their characteristics match the parameters of the target audience of the advertisement. Consumer motives are important as they help us understand what influences them when making purchasing decisions.

The aim of the research will be to find out how advertisers were willing to invest in Internet advertising in the years 2012-2020 and how the phenomenon affected the amount of investment in other forms of advertising in the Czech Republic through the following established research questions: What is the development in the Czech Republic investing in internet advertising? What is the relationship between investing in online advertising and other types of advertising?

\section{Methodology}

The aim of this paper is to find out how advertisers were willing to invest in Internet advertising in 2012-2020 and how the phenomenon affected the amount of investment in other forms of advertising in the Czech Republic. The data were obtained from questionnaire surveys and were based on the annual financial statements of the surveyed subjects, published annually by the Association for Internet Development (SPIR). In order to maintain the protection of sensitive information, the ppm factum agency was entrusted with the processing of these investigations for the years 2012-2015. For the years 2016-2020, the MEDIAN agency was entrusted with their processing [14]. The research dataset will include Internet operators whose media dominate the Czech market and thus affect the majority of Internet users. The performance of other types of media types will be determined based on data by Nielsen Admosphere agency.

The research methodology will include the following procedure:

1) We analyze the obtained data using a comparative method.

2) Then we process the data in Google Sheets.

3) The cost values for the calendar years will be assigned in rows to the corresponding columns, which will represent specific years, and the percentage share of investments in individual types of ads in the total advertising investments in a given year will also be expressed. For each one year, a new column will be created, in which the amount of increase or decrease in investment will be determined by deducting the monetary value of the zero year from the costs for the year under review. The year-on-year change will be expressed in both monetary and percentage values.

4) Subsequently, the values found for the years 2012-2020 will be compared with each other.

The obtained results will be demonstrated by means of a graphical representation in the following chapter.

\section{Results and Discussion}

Based on the proposed methodology of input data processing, the amount and percentage of investments made in the advertisement and in its individual media types was determined. Figure 1 graphically shows the observed values of advertising investments. 


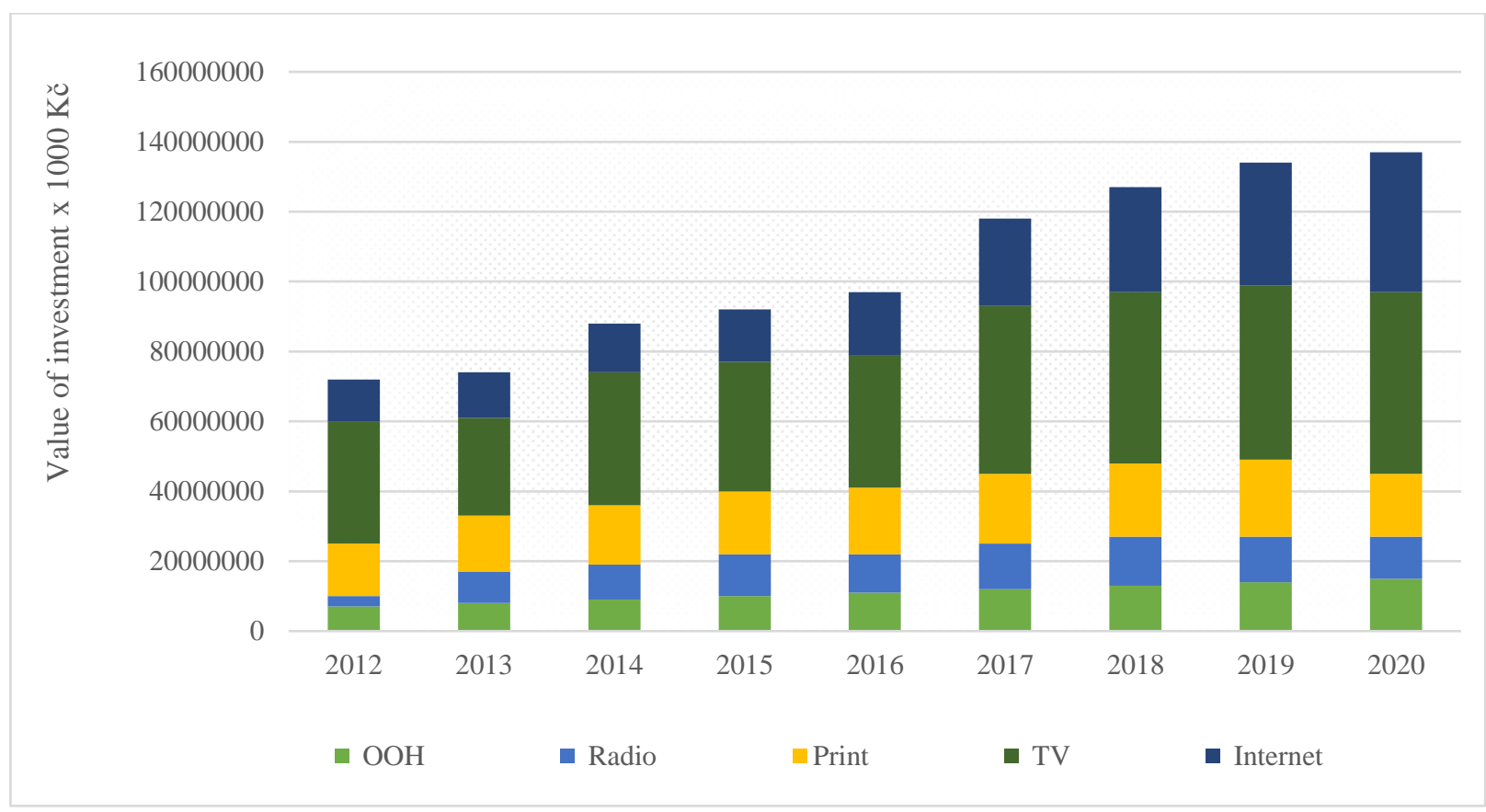

Figure 1. Development of investments in advertising in the Czech environment

Source: Author.

Investments made in the Czech advertising market have doubled over the period under review and show constant growth every calendar year. The amount within the total absolute investments was CZK 63.99 billion in 2012 , but in 2020 it already reached the amount of CZK 130.55 billion. Within 2013, total investment in advertising increased by CZK 5.52 billion.

Developments in online advertising investment have been growing for a long time. Year-on-year absolute growth within individual years was CZK 2.16 billion in 2013, CZK 1.28 bn. in 2014, CZK 0.46 billion in 2015, CZK 4.68 billion in 2016, CZK 3.58 billion in 2017, CZK 5.28 bn. in 2018, CZK 5.78 bn. in 2019 and CZK 5.14 billion in 2020. As for the largest year-on-year financial increase, it was recorded in 2019. The smallest absolute increase in investments was recorded in 2015.

In the long run, the most invested advertising medium - television advertising - is showing steady absolute growth similar to the case of Internet advertising. However, 2013 was an exception, as there was a one-off decrease in investments by CZK 2.32 billion (-7.69\%). In 2016, the highest absolute and relative growth was recorded, when investments increased by CZK 6.88 billion (19.39\%).

Currently, the third most important advertising channel after TV and the Internet - the press - also recorded its best result in 2016, when investments increased by CZK 1.16 billion $(6.47 \%)$ but shows a long-term stagnation in contrast to the two most successful types of advertising. The years in which the press showed a negative increase in invested funds were $2014(-0.78 \%), 2015(-0.07 \%)$ and $2020(-13.06 \%)$.

In 2013, radio advertising recorded a record growth, when investments in it increased by $447.15 \%$. In 2018, advertisers spent the most funds, namely CZK 8.04 billion. (10.37\%). Absolute year-on-year growth over the last two years showed a decrease in investments in 2019 by $-1.35 \%$ and in 2020 by -8.02 .

$\mathrm{OOH}$ advertising was the last monitored medium in which investments fell by $-19.44 \%$ in 2020 . In previous years, however, no extreme was recorded in the year-on-year absolute development of investments.

Subsequently, an analysis of the share of media types in the total investment in advertising was performed, graphically shown in Figure 2. 


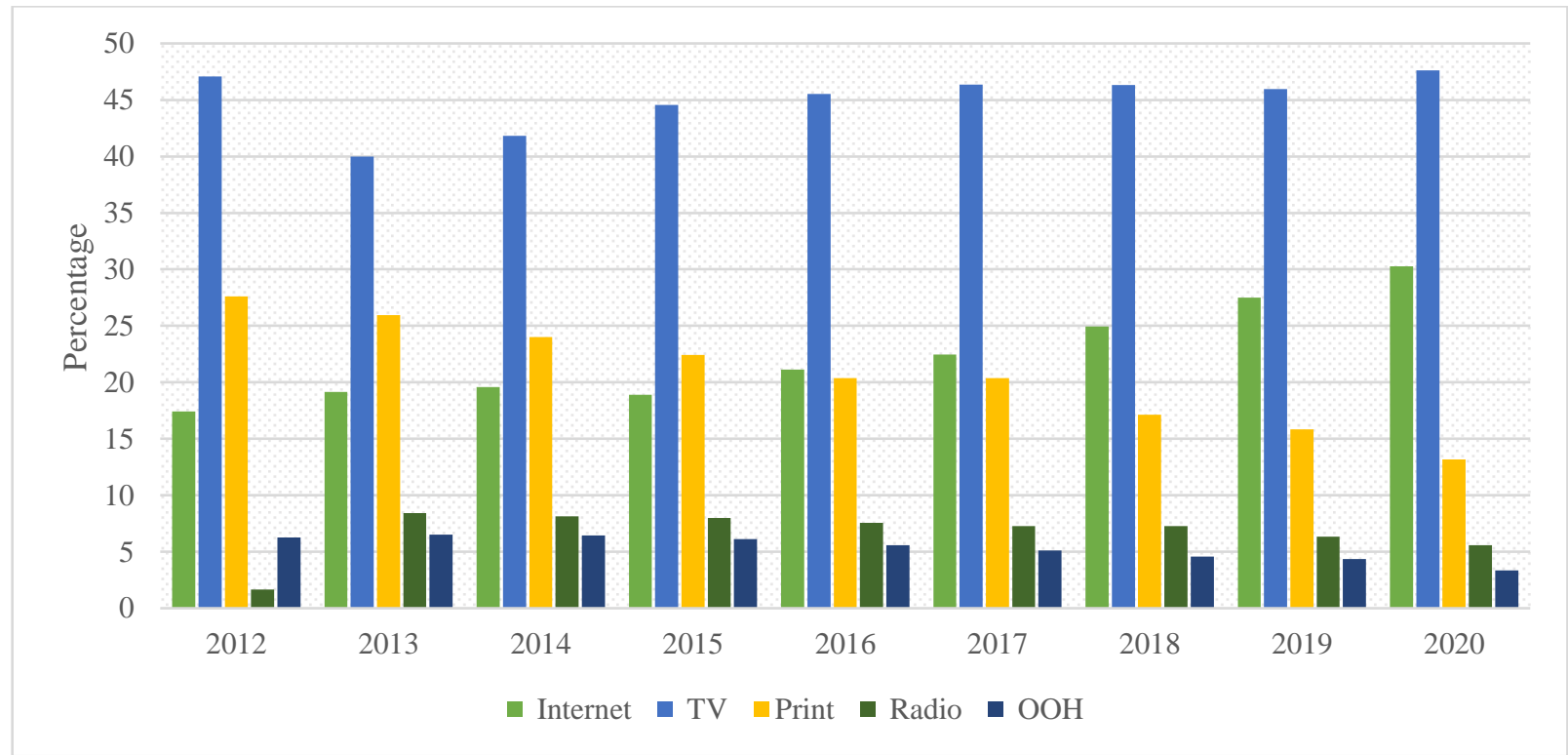

Figure 2. The share of media types in total investment in advertising

Source: Author.

The development of the share of investments in individual media types in the total investments in advertising was as follows: the most invested type in 2012 was television advertising, representing $47.06 \%$ of all investments. This was followed by the press with $27.59 \%$, followed by the Internet with $17.43 \%$, OOH with $6.25 \%$ and finally radio with $1.67 \%$. The share of TV advertising in 2013 fell to $39.99 \%$ and the share of print to $25.95 \%$. In the given year (2013), on the other hand, an increase in Internet advertising to $19.14 \%$, radio advertising to $8.41 \%$ and OOH to $6.51 \%$ was recorded. A slight increase in TV advertising (41.83\%) and Internet advertising (19.57\%) at the expense of print advertising $(24.01 \%)$, radio $(8.13 \%)$ and $\mathrm{OOH}(6.46 \%)$ was recorded in 2014 . TV advertising in 2015 strengthened and took up $44.54 \%$ and the share in all other media was reduced, namely the share of Internet advertising was reduced to $18.88 \%$, the share of print advertising to $22.44 \%$, the share of radio advertising in $8.01 \%$ and the $\mathrm{OOH}$ content to $6.13 \%$. TV advertising (45.37\%) and Internet advertising $(21.12 \%)$ increased in 2016, while advertising in the press $(20.39 \%)$, radio $(7.55 \%)$ and $\mathrm{OOH}$ $(5.58 \%)$ decreased. TV advertising $(46.34 \%)$ and Internet advertising $(22.46 \%)$ are growing again in 2017 , the share of print advertising $(20.39 \%)$, radio $(7.28 \%)$ and $\mathrm{OOH}(5.11 \%)$ decreases. The only medium that recorded an increase in market share in 2018 is the Internet $(24.95 \%)$, the share of TV advertising (46.31\%), print advertising (17.13\%), radio $(7.28 \%)$ and $\mathrm{OOH}(4.59 \%)$ decreased. This trend continues in 2019, when the share of Internet advertising increased to $27.50 \%$ and, conversely, the share of TV advertising $(45.97 \%)$, print advertising $(15.84 \%)$, radio $(6.35 \%)$ and $\mathrm{OOH}$ $(4.35 \%)$ decreased. Growth was recorded in 2020 in the case of Internet $(30.26 \%)$ and TV advertising $(47.61 \%)$ Advertising in the press $(13.19 \%)$, radio $(5.59 \%)$ and $\mathrm{OOH}(3.35 \%)$ decreased. In Graph 2, the findings are shown graphically.

Based on the obtained results, the determined research questions can be answered:

What is the development of investments in Internet advertising in the Czech Republic?

Investments in Internet advertising show steady growth, with their market share increasing from $17.43 \%$ in 2012 to $30.26 \%$ in 2020 . No negative growth in its investments was recorded in any calendar year, which is a unique finding, as for all other types of advertising media, at least one such year has been recorded. The results show that online advertising is growing, and advertisers are willing to invest more and more money in it. The increase in the number of Internet users can explain the stable growth of investments, which makes the environment even more attractive for advertisers.

What is the relationship between investing in online advertising and other types of advertising?

No direct dependence was found between Internet and television advertising. As for the share of TV advertising in the total advertising investment, even during the dramatic increase in investment in Internet advertising, it remains at similar values for the entire period under review and maintains its position as a leader in the advertising market. However, it is different in the case of print advertising, which saw a dramatic decline in market share from $27.59 \%$ in 2012 to $13.19 \%$ in 2020 . It can be stated that this is due to its direct dependence on the willingness of investors to invest in online advertising. In the case of $\mathrm{OOH}$ advertising, there has been a significant decline, with its market share falling from $6.25 \%$ in 2012 to $3.35 \%$ in 2020. In this case, it can also be stated that there is a direct dependence on online advertising. Radio advertising is also showing a declining trend, but it is not as dramatic as in the case of print advertising and OOH advertising. It is therefore not possible to prove a relationship between investment in internet and investment in radio advertising. 
At the expense of online advertising, print advertising and $\mathrm{OOH}$ advertising are the most neglected advertising media by advertisers. In the case of print advertising, this development can be explained by the growing number of mobile users and also by the declining willingness of people to read print media, but these media began to create content in the online environment, where they offer paid advertising. However, the value of a given advertisement is already included in the investment in internet advertising. Thus, a decrease in market share in this case does not necessarily mean a decrease in the revenues that companies earn from paid advertising. However, similar possibilities are not offered to OOH advertising operators and therefore the result of the given contribution can serve as a basis for subsequent research into the usability of $\mathrm{OOH}$ advertising in the coming years.

\section{Conclusion}

Technology has become an integral part of the market economy. It is not discussed in the scientific world, not only is the question of their need being addressed, but their scope for use in SMEs is also being examined. The aim of the paper was to analyze the development of investment in online advertising in the Czech Republic during 2012-2020 and to determine whether there is a relationship between the development of investment in Internet advertising and other types of advertising, such as TV, print, radio and $\mathrm{OOH}$ advertising. The results show that investments in online advertising are still growing and each year occupy a larger market share in the total investment in advertising.

Potential for further research: There is an assumption that the growth of investment in online advertising will continue in the coming years due to constant technological progress and constant growth in the technical literacy of users. However, the question remains as to what effect this increase will have on television advertising and its hitherto dominant position, and whether the given trend will not lead to a revolution in the advertising market and also to the extinction of certain media types.

Application in practice: The results of the research will help both researchers and companies in the process of their decision to invest in selected types of advertising.

\section{Acknowledgments}

This contribution is a partial output of the work on the project VEGA MŠ SR no. 1/0140/21.

\section{References}

1. Czech Statistical Office. Podil nakupujících na internetu se meziročně zvýšil z 39 na 54 \% [online]. Available at: https://www.czso.cz/csu/czso/podil-nakupujicich-na-internetu-se-mezirocne-zvysil-z-39-na-54- (2020)

2. M. Misuraca, G. Scepi, M. Spano. A network-based concept extraction for managing customer requests in a social media care context. International Journal of Information Management. 51(101956) (2019)

3. N. A. Vila, L. Cardoso, A. F. de Araujo. Communication 2.0 in the Spanish Tourism Sector: An Analysis Of The Official Tourism Promotion Websites. International Journal of Marketing, Communication and New Media. 5(5), 5-25 (2019)

4. M. O. Opresnik. Effective Social Media Marketing Planning - How to Develop a Digital Marketing Plan. Social Computing and Social Media - LNCS. 10913, 333-341 (2018)

5. F. Pollák, R. Vavrek, J. Váchal, P. Markovič, M. Konečný. Analysis of Digital Customer Communities in terms of their interactions during the first wave of the COVID-19 pandemic. Management and Marketing. 16(2), 134-151 (2021)

6. O. Khurramov, S. A. Fayzieva. The main convenience of internet marketing from traditional marketing. Academy. 1(52), 30-32 (2020)

7. S. Khajehasani, A. Abolizadeh, L. Dehyadegari. The role of management and strategy in the development of Emarketing. Recent Advances in Computer Science and Communications. 13(4), 641-649 (2020)

8. J. Soviar, M. Holubčík, J. Vodák, M. Rechtorík, F. Pollák. The Presentation of Automotive Brands in the On-Line Environment - The Perspective of KIA, Peugeot, Toyota and VW in the Slovak Republic. Sustainability. 11, 2132 (2019)

9. F. Pollák, P. Markovič. Size of Business Unit as a Factor Influencing Adoption of Digital Marketing: Empirical Analysis of SMEs Operating in the Central European Market. Administrative Sciences. 11(3), 71 (2021)

10. V. Kumar, S. Mittal. Mobile marketing campaigns: Practices, challenges and opportunities. International Journal of Business Innovation and Research. 21(4), 523-539 (2020)

11. D. Brown, N. Hayes. Influencer marketing. Routledge: Taylor \& Francis Group (2008) 
12. H. Zhang, W. Zhang, Y. Rong, K. Ren, W. Li, J., Wang. Managing risk of bidding in display advertising. Proceedings of the 10th ACM International Conference on Web Search and Data Mining (WSDM 2017). 581-590 (2017)

13. V. Gasilov, M. Karpovich, M. Preobrazhensky, K. Borodin, T. Dao. Optimization of advertising media placement on transport infrastructural sites on the basis of big data technologies. IOP Conference Series: Materials Science and Engineering. 890 (2020)

14. Průzkum interních výkonů SPIR. Zadavatelé v loňském roce investovali do internetové reklamy 39,5 miliard korun [online]. Available at: http://www.inzertnivykony.cz/ (2020) 